\title{
Regional variations of symptoms of the chronic venous disease among primary health care patients in Poland
}

Damian Ziaja', Mariola Sznapka², Joanna Grzela ${ }^{3}$, Jacek Kostecki², Grzegorz Biolik², Krzysztof Pawlicki ${ }^{4}$, Krzysztof Ziaja ${ }^{2}$, Jerzy Chudek ${ }^{5}$, Marek Maruszynski ${ }^{6}$, Aleksander Molski ${ }^{7}$, Aleksander Sieron ${ }^{8}$

'Physiotherapy Centre of the Physiotherapy Department, Faculty of Health Sciences, Silesian Medical University in Katowice, Poland

${ }^{2}$ Department and Clinic of General and Vascular Surgery, Faculty of Medicine, Silesian Medical University in Katowice, Poland ${ }^{3}$ LEKAM, Company with limited liability

${ }^{4}$ Biophysics Centre of the Department of Medical Biophysics, Faculty of Medicine in Katowice, Silesian Medical University in Katowice, Poland

${ }^{5}$ Pathophysiology Centre of the Department of Pathophysiology, Faculty of Medicine in Katowice, Silesian Medical University in Katowice, Poland

${ }^{6}$ Regional coordinator; The Military Medical Institute in Warsaw, Poland

${ }^{7}$ Regional coordinator; Department and Clinic of General and Vascular Surgery, Faculty of Medicine, Collegium Medicum named after Ludwik Rydygier in Bydgoszcz Nicolaus Copernicus University in Torun, Poland

${ }^{8}$ Regional coordinator; Department and Clinical Ward of Internal Diseases, Angiology and Physical Medicine, Faculty of Medicine with the Division of Dentistry in Zabrze, Silesian Medical University in Katowice, Poland

The presented results were collected in the context of the PHLEBOS-2 research (multi-centre epidemiological study of patients suffering from chronic venous disease) carried out under the scientific grant of LEKAM Company with limited liability in the years $201 \mathrm{I}-2012$.

\section{Abstract}

Introduction. The diverse social and cultural contexts may cause differences in perceiving symptoms of the chronic venous disease (ChVD), not only in global, European terms, but also in a regional context. The purpose of the study was to find the regional differences of the reported symptoms and the applied conservative treatment methods among patients with ChVD diagnosed by the primary health care (PHC) doctors in Poland. Material and methods. 13393 patients participated in the multi-centre PHLEBOS-2 research carried out by 330 PHC doctors in 15 voivodeships.

Results. In the study group of patients, $31.9 \%$ of patients had ChVD symptoms - the $C_{0}$ stage, telangiectasias and venulectasias ( $C$, stage) occurred among $56.1 \%$ of patients, varices without symptoms of venous insufficiency occurred among $6 \%$ of patients and venous insufficiency among $6 \%$ of patients. Venous ulcers (active or healed) occurred among $0.6 \%$ of subjects. Essential differences in the ChVD structure between voivodeships were noted.

Among the most frequently reported ChVD ailments were heaviness of legs (72.9\%), ankle swelling in the evenings (68.4\%) and nighttime leg cramps (58.6\%). Leg swelling during the night hours occurred less frequently - 39.8\%, paraesthesias - 30.4\%, restless legs syndrome - 18.6\%. The average intensity of calf pain was

Address for correspondence: Damian Ziaja, Physiotherapy Centre of the Physiotherapy Department, Faculty of Health Sciences, Silesian Medical University in Katowice, Ziolowa 45/47, 40-635 Katowice 
moderate $(3.82 \pm 1.86$ points in the 10 point scale). The territorial diversity in the prevalence of symptoms was significant and resulted neither from the ChVD seriousness, nor from the age of the patients.

Compression therapy was applied on average by $12.5 \%$ of patients and $24.8 \%$ of patients used phlebotropic drugs with large territorial variations (respectively from 3.4\% to $28.8 \%$ and from 11 . 2 to $56.1 \%$ ). The differences between the voivodeships were greater than the regional differences and did not depend on the ChVD stage. Conclusions. There are significant territorial variations in Poland in the frequency of the reported symptoms and in the conservative therapy of the chronic venous disease.

Key words: chronic venous diseases, venous insufficiency, restless legs syndrome, varicose veins

Acta Angiol 2015; 21, 2: 31-39

\section{Introduction}

It is estimated that about $63 \%$ of the world population suffers from chronic venous disease (ChVD) of the lower extremities $\left(\mathrm{C}_{1}-\mathrm{C}_{6}\right.$ stages $)$ and $9.6 \%$ has symptoms of venous insufficiency $C_{3}$ to $C_{6}$ according to the CEAP (Clinical, Etiologic, Anatomic, Patophysiologic) classification [I]. However, venous ulcers occur among $\mathrm{I}-2 \%$ of patients $[\mathrm{I}, 2]$. The epidemiological studies show a significant regional diversity of the morbidity rate $[I, 2]$. A milestone in the epidemiological studies was the systematization of the disease and its division into 7 stages in 1994 - the CEAP classification, which is commonly accepted in the updated version of 2004 [3].

The ChVD epidemiology in Poland was rarely investigated. The first significant study was carried out more than 10 years ago [4]. This study covered 40095 adult patients who contacted 803 family doctors and gynaecologists seeking help for any reason. On account of a significant participation of gynaecologists, the percentage of women participating in this study was as high as $84 \%$. $51 \%$ of women and $38 \%$ of men had ChVD symptoms. Venous insufficiency (stage $\mathrm{C}_{3-6}$ ) was diagnosed among $10 \%$ of subjects and the past and active ulcers occurred among $1.5 \%$ of patients. Among the ChVD symptoms (stages $\mathrm{C}_{1-6}$ ) reported by the patients, the most frequently occurring were: pain ( $70 \%$ of men and $77 \%$ of women), heaviness of legs ( $67 \%$ of men and $75 \%$ of women), cramps $(61 \%$ of men and $57 \%$ of women) and swelling (48\% of men and $57 \%$ of women). Only $23 \%$ of patients with ChVD applied conservative treatment recommended to tackle this disease (phlebotropic drugs, compression therapy).

Later, the epidemiological studies conducted in Poland analyzed the main aspects of treating patients suffering from ChVD, such as compression therapy and pharmacotherapy. It was ascertained that only $25.6 \%$ of the patients who were treated by primary health care doctors applied compression therapy, partly due to the fact that this form of therapy was not duly propagated by family doctors [5], as well as, due to rejecting it by a lot of patients because of high therapy costs (33.0\%), sweating $(27.3 \%)$, itchiness ( $13.6 \%)$, cosmetic reasons (I3.6), edema intensification (6.8\%), exudate $(3.4 \%)$ and application difficulties (2.3\%) [6]. The percentage of patients who do not approve of the compression therapy decreases with the progression of the disease to $27.3 \%$, in stage $\mathrm{C}_{6}$ according to CEAP classification [7].

In the era of aggressive TV, radio and newspaper advertisements, the most widespread treatment method among the patients with ChVD is pharmacotherapy, being often changed after seeing a consecutive advertisement of "a significantly better" drug. Phlebotropic drugs are accepted by over $95 \%$ of patients entering ChVD treatment [7].

If the compression therapy is not applied regularly or it is discontinued, the disease progresses and the treatment costs incurred by the health care system increase. According to the data of NFZ (National Health Fund) 4I-44 thousand vein surgeries of lower extremities were carried out annually in Poland in the years 2009-20I3, most frequently saphenous veins were removed with the varicose veins. The NFZ data do not include all surgeries, especially those advanced ones which are still not reimbursed.

The perceptions of one's own disease by patients is a complex process depending on the possessed knowledge and convictions as to its significance in view of their past life.

The individual features of people related to behaviour focused on the reduction of psychological stress and related to health measures determining the course of a given disease, have a significant impact on the mental condition, functioning of the patient. These features, as well as accessibility to medical services also determine actions taken by the patients, including such actions as obtaining medical aid and self-medication. More and more patients decide to start treatment after looking up information on the Internet and watching and reading advertisements in the mass media. 
Different social and cultural variations may be caused by a different way of perceiving the ChVD symptoms not only in global, European terms, but also in a regional context. That is why the purpose of this study was to explore regional differences of the reported symptoms and the applied methods of conservative treatment among patients with ChVD diagnosed by the primary health care (POZ) doctors in Poland.

\section{Material and methods}

The PHLEBOS- 2 research was conducted by 330 primary health care doctors in 15 out of 16 voivodeships. Patients with ChVD symptoms, who have not taken the phlebotropic drugs for at least 30 days and consulted the physicians, were successively recruited to the PHLOBOS-2 research. The criteria which ruled out the participation in the PHLEBOS research were: pregnancy, decompensated heart defects, congestive heart failure, chronic obstructive pulmonary disorder (COPD), liver cirrhosis, advanced cancer, atherosclerosis of lower extremities (with an ankle-brachial index $|A B| /$ of $<0.85$ ), ulceration of the lower legs of a different etiology, patients with a significant disability caused by the osteoarticular diseases or postictal states. For carrying out the research, the approval of the Bioethics Committee of the Silesian Medical University was obtained. Each patient gave his/her informed consent for taking part in the study.

The research protocol assumed the baseline assessment of the disease progression in the CEAP scale $\left(\mathrm{C}_{0}-\mathrm{C}_{6}\right)$, of the occurring symptoms and ailments (swelling, heavy legs, night cramps, burning sensation and paraesthesias, restless legs syndrome, the assessment of calf pain intensity and the subjective assessment of the state of health in the VAS analog scale, measurements of circumferences of both lower limbs at an ankle level, $1 / 2$ of the leg length below the knee and $I / 3$ of the length of the lower part of the thigh.

The research project assumed the recruitment of 16 thousand patients. After rejecting the incomplete protocols $(n=1956)$, a group of 13393 patients with ChVD was analyzed and furthermore $65 \mathrm{I}$ patients with $\mathrm{C}_{2}$ progression or a higher one were referred for further treatment in the Vascular Clinics.

\section{Analysis of data}

The analysis compares the ChVD progession in the CEAP scale, the frequency of the symptoms reported by the patients, the frequency of applying compression therapy in respective voivodeships in relation to average values for the entire study group (Poland) prior to the application of phlebotropic drugs.

\section{Statistical analysis}

A statistical analysis was carried out using the STATISTICA IO PL programme.

Variable values were presented as average values with a standard deviation. The chi-square test was applied for comparing the prevalence of features and the Student's t-test compared the difference between variances. The value of $p<0.05$ was adopted as the value for statistical significance.

\section{Results}

\section{Profile of the study group}

Among 13393 patients participating in the study, $83.6 \%$ were living in cities and $16.4 \%$ in rural municipalities (Table I). In comparison with the data of GUS (Main Statistical Office) 2012 (rural population 39.4\%), there was an essential over-representation of the urban population in the trial population. Coexisting chronic diseases were reported among $33.4 \%$ of subjects. The symptoms of ischaemia of the lower extremities were reported by $12.0 \%$ of patients (claudication distance $<500 \mathrm{~m}-10.2 \%$ and $<200 \mathrm{~m}-1.8 \%) .48 .8 \%$ performed sedentary jobs and $37.2 \%$ of the subjects worked in a standing position. Significant variations between the voivodeships and even within the regions were ascertained (Table 2), amounting to $20 \%$ for those performing sedentary work and $15 \%$ for those working in a standing position. There was also diversity among the patients performing hard physical work.

\section{Progression of the chronic venous disease}

In the patient study group, $31.9 \%$ of patients only had ChVD symptoms - stage $\mathrm{C}_{0}, 56.1 \%$ had telangiectasias and venulectasias (stage $\mathrm{C}_{1}$ ), $6 \%$ had varices without symptoms of venous insufficiency and $6 \%$ suffered from venous insufficiency (Table 3 ). Active or healed venous ulcers occurred among $0.6 \%$ of subjects. Substantial differences in the ChVD structure were noted in some parts of the Podkarpackie, Podlaskie, Świętokrzyskie, Pomorskie and Warmińsko-Mazurskie Voivodeships. The lowest percentage of patients in stage $\mathrm{C}_{0}$ was reported in the Warmińsko-Mazurskie Voivodeship (6.6\%), the Świętokrzyskie Voivodeship (I5.1\%) and the Podlaskie Voivodeship (19.1\%), whereas, the highest percentage was noted in the Pomorskie Voivodeship (4I.1\%). The above compilation did not include data of patients with venous insufficiency in four provinces - the Podlaskie, Warmińsko-Mazurskie, Opolskie and Podkarpackie Voivodeships. However, the primary health care doctors in the Świętokrzyskie Voivodeship diagnosed venous insufficiency among as many as $45.7 \%$ of the subjects. 
Table I. Demographic characteristics of patients suffering from the chronic venous disease with the division into regions and voivodeships

\begin{tabular}{|c|c|c|c|c|c|}
\hline & \multirow[t]{2}{*}{ Age (years) } & \multicolumn{4}{|c|}{ Place of residence (\%) } \\
\hline & & Village & $\begin{array}{c}\text { Towns }<10 \\
\text { thousand residents }\end{array}$ & $\begin{array}{l}\text { Cities } 10-100 \\
\text { thousand residents }\end{array}$ & $\begin{array}{l}\text { Cities }>100 \\
\text { thousand residents }\end{array}$ \\
\hline Poland [ $n=13$ 393] & $50 \pm 14$ & 16.4 & 8.8 & 24.9 & 49.9 \\
\hline \multicolumn{6}{|l|}{ Central Region } \\
\hline Łódzkie [n = II80] & $52 \pm 15$ & 19.1 & 3.6 & 14.4 & 62.9 \\
\hline Mazowiecki [n = 1604] & $51 \pm 14$ & 11.5 & 5.4 & 19.5 & 63.5 \\
\hline \multicolumn{6}{|l|}{ Southern Region } \\
\hline Małopolskie $[\mathrm{n}=1021]$ & $51 \pm 14$ & 41.9 & 11.8 & 11.6 & 34.6 \\
\hline Śląskie [n = 2238] & $50 \pm 13$ & 4.3 & 5.0 & 32.2 & 58.5 \\
\hline \multicolumn{6}{|l|}{ Eastern Region } \\
\hline Lubelskie [n = 947] & $48 \pm 15$ & 23.6 & 10.5 & 44.8 & 21.1 \\
\hline Podkarpackie $[\mathrm{n}=44 \mathrm{I}]$ & $53 \pm 12$ & 39.8 & 32.7 & 27.2 & 0.2 \\
\hline Podlaskie $[\mathrm{n}=382]$ & $46 \pm 13$ & 6.6 & 10.3 & 12.4 & 70.7 \\
\hline Świętokrzyskie [n = I23] & $58 \pm 16$ & 44.2 & 5.8 & 49.2 & 0.8 \\
\hline \multicolumn{6}{|l|}{ Western Region } \\
\hline Wielkopolskie [n = 2014] & $47 \pm 14$ & 15.4 & 15.7 & 30.3 & 38.7 \\
\hline Zachodniopomorskie $[\mathrm{n}=480]$ & $51 \pm 13$ & 8.8 & 6.6 & 33.3 & 51.3 \\
\hline \multicolumn{6}{|l|}{ South-western Region } \\
\hline Dolnośląskie [n = 828] & $53 \pm 13$ & 12.8 & 5.7 & 12.8 & 68.6 \\
\hline Opolskie $[n=463]$ & $53 \pm 12$ & 23.4 & 19.3 & 46.8 & 10.6 \\
\hline \multicolumn{6}{|l|}{ Northern Region } \\
\hline Kujawsko-Pomorskie $[n=734]$ & $51 \pm 15$ & 4.5 & 1.3 & 2.5 & 91.7 \\
\hline Pomorskie $[\mathrm{n}=778]$ & $46 \pm 14$ & 13.0 & 3.9 & 32.6 & 50.5 \\
\hline Warmińsko-Mazurskie $[\mathrm{n}=160]$ & $57 \pm 12$ & 48.8 & 0 & 0 & 51.3 \\
\hline
\end{tabular}

\section{Symptoms of the chronic venous disease}

Among the most frequently reported ChVD ailments were: heaviness of legs (72.9\%), ankle swelling in the evenings $(68.4 \%)$ and nighttime leg cramps $(58.6 \%)$. The remaining symptoms occurred among less than half of the subjects (leg swelling during the evening hours $-39.8 \%$, paraesthesias - $30.4 \%$, restless legs syndrome - $18.6 \%)$. The average intensity of calf pain was moderate $(3.82 \pm 1.86$ points in the 10 point scale; Table 4).

The prevalence of symptoms showed a substantial territorial diversity. Ankle swelling during the evening hours was more frequently reported by doctors from the Łódzkie Voivodeship and more seldomly by doctors in the Śląskie, Podkarpackie and Kujawsko-Pomorskie Voivodeships. Leg swelling during the evening hours was reported most seldomly in the Śląskie and Kujawsko-Pomorskie Voivodeships. As far as other cases than ankle swelling are concerned, there was a disproportionately high ratio of leg swelling record- ed during the afternoon hours in other voivodeships (Małopolskie, Świętkorzyskie, Zachodniopomorskie, Opolskie and Warmińsko-Mazurskie). A big variability of frequency was noted for the recorded swellings. From merely $0.6-1.3 \%$ in the Warmińsko-Mazurskie Voivodeship to $70.7 \%$ in the Świętkorzyskie Voivodeship. The heaviness of legs rarely coincided with the prevalence of swellings. The convergence of symptoms was recorded for the Mazowieckie and Kujawsko-Pomorskie Voivodeships. Disproportionately heaviness was reported by patients from the Lubelskie, Podlaskie, Warmińsko-Mazurskie and Pomorskie Voivodeships. No relation between the heaviness of legs and calf pain intensification was noted.

Nighttime leg cramps were reported by patients from the Podlaskie, Świętokrzyskie and Zachodniopomorskie Voivodeships and more seldomly from the Opolskie and Warmińsko-Mazurskie Voivodeships. The prevalence of cramps was not linked to paraesthesia and the restless legs syndrome. 
Table 2. Analysis of the performed work by patients suffering from chronic venous disease with the division into regions and voivodeships

\begin{tabular}{|c|c|c|c|c|}
\hline & \multicolumn{4}{|c|}{ Place of residence (\%) } \\
\hline & $\begin{array}{c}\text { Sedentary work } \\
>6 \mathrm{~h} / \mathrm{d}\end{array}$ & $\begin{array}{l}\text { Work in a standing } \\
\text { position }>6 \mathrm{~h} / \mathrm{d}\end{array}$ & $\begin{array}{l}\text { Hard physical work } \\
\qquad 66 \mathrm{~h} / \mathrm{d}\end{array}$ & Other \\
\hline Poland $[n=13$ 393] & 48.8 & 37.2 & 10.7 & 3.4 \\
\hline \multicolumn{5}{|l|}{ Central Region } \\
\hline Łódzkie [n = II80] & 51.6 & $32.5 *$ & $13.7^{* *}$ & $2.3^{*}$ \\
\hline Mazowieckie [n = 1604] & $58.5^{\wedge}$ & $31.2 * *$ & $7.9 * *$ & $2.4^{*}$ \\
\hline \multicolumn{5}{|l|}{ Southern Region } \\
\hline Małopolskie [n = 102I] & 48.0 & 34.2 & $15.3^{\wedge}$ & 2.5 \\
\hline Śląskie [n = 2238] & 48.9 & 40.3 & $7.4^{\wedge}$ & 3.5 \\
\hline \multicolumn{5}{|l|}{ Eastern Region } \\
\hline Lubelskie [n = 947] & $35.3^{\wedge}$ & 40.8 & $17.2^{\wedge}$ & $6.7^{\wedge}$ \\
\hline Podkarpackie [n = 44I] & 55.1 & 32.6 & 9.8 & 2.6 \\
\hline Podlaskie [n = 382] & 45.0 & $45.3^{*}$ & 6.8* & 2.9 \\
\hline Świętokrzyskie [n = 123] & 59.7 & 30.6 & 8.1 & 1.6 \\
\hline \multicolumn{5}{|l|}{ North-western Region } \\
\hline Wielkopolskie $[n=2014]$ & 47.3 & 39.7 & $8.0^{\wedge}$ & $5.1^{\wedge}$ \\
\hline Zachodniopomorskie $[\mathrm{n}=480]$ & 50.7 & 34.6 & 11.9 & 2.7 \\
\hline \multicolumn{5}{|l|}{ South-western Region } \\
\hline Dolnośląskie [n = 828] & 50.1 & 36.4 & 10.2 & 3.3 \\
\hline Opolskie $[n=463]$ & 46.1 & 36.2 & $16.7^{\wedge}$ & $1.1 * * *$ \\
\hline \multicolumn{5}{|l|}{ Northern Region } \\
\hline Kujawsko-Pomorskie [n = 734] & $42.5^{*}$ & 38.7 & $15.6^{\wedge}$ & 3.3 \\
\hline Pomorskie [n = 778] & 48.6 & 40.2 & 8.9 & 2.4 \\
\hline Warmińsko-Mazurskie [n = I60] & 51.2 & 44.6 & $3,3 * *$ & 0.8 \\
\hline
\end{tabular}

Statistical significance in relation to "Poland" $\chi^{2}-{ }^{*} \mathrm{p}<0.05$; **p $<0.0 \mathrm{I} ; \wedge \mathrm{p}<0.00$ I

These ailments showed big variations between the voivodeships, yet not between the regions (Table 4).

\section{Quality of life of patients with chronic venous disease}

The subjects perceived the quality of life in different regions and voivodeships in a similar way (Table 4). The lowest quality of life was reported by patients living in the Podlaskie Voivodeship and the highest quality of life was reported in the Kujawsko-Pomorskie Voivodeship. The quality of life in these voivodeships was related neither to the seriousness of ChVD, nor the age of the patients.

Application of compression therapy and phlebotropic drugs by the patients in the past

The compression therapy was applied on average by $12.5 \%$ of patients. Among the frequently used compression products were knee socks $(5.4 \%)$ and stockings/tights (5.2\%) - Table 5.

Bandages $(2.1 \%)$ were more seldomly used by patients. The differences between voivodeships were greater than regional differences. Compression products were used most frequently by patients from Zachodniopomorskie Voivodeship (28.8\%) and most seldomly by patients from the Podlaskie and Świętokrzyskie Voivodeships ( 3.4 and $4.1 \%$ respectively). The frequency of using the compression products in respective voivodeships did not depend on the ChVD progession.

In the past only every fourth patient $(n=3272)$ took phlebotropic drugs and there was a large territorial diversity - from II.2 to $56.1 \%$ (Table 5).

\section{Discussion}

The results of the conducted analysis indicate that the early stages of the chronic venous disease are dia- 
Table 3. Progression of the chronic venous disease with division into regions and voivodeships

\begin{tabular}{|c|c|c|c|c|c|c|c|}
\hline & $\mathrm{C}_{0}$ & $C_{1}$ & $\mathrm{C}_{2}$ & $\mathrm{C}_{3}$ & $\mathrm{C}_{4}$ & $\mathrm{C}_{5}$ & $\mathrm{C}_{6}$ \\
\hline Poland [n = I 3 393] & $31.9 \%$ & $56.1 \%$ & $6.0 \%$ & $4.0 \%$ & $1.4 \%$ & $0.4 \%$ & $0.2 \%$ \\
\hline \multicolumn{8}{|l|}{ Central Region } \\
\hline Łódzkie [n = II80] & $35.4 \%$ & $55.4 \%$ & $2.6 \%^{\wedge}$ & $5.0 \%$ & $1.3 \%$ & $0.2 \%$ & $0.1 \%$ \\
\hline Mazowieckie [n = 1604] & $24.4 \%^{\wedge}$ & $57.9 \%$ & $7.9 \% * *$ & $5.3 \% *$ & $2.9 \%^{\wedge}$ & $0.7 \%$ & $0.9 \%^{\wedge}$ \\
\hline \multicolumn{8}{|l|}{ Southern Region } \\
\hline Małopolskie [n = 102I] & $25.9 \% * *$ & $56.4 \%$ & $7.4 \%$ & $6.9 \% \wedge$ & $2.7 \% \wedge$ & $0.6 \%$ & $0.1 \%$ \\
\hline Śląskie [n = 2238] & $37.2 \%$ *** & $56.5 \%$ & $3.1 \%^{\wedge}$ & $2.7 \% * *$ & $0.3 \%^{\wedge}$ & $0.1 \% *$ & $0.1 \%$ \\
\hline \multicolumn{8}{|l|}{ Eastern Region } \\
\hline Lubelskie [n = 947] & $33.8 \%$ & $58.3 \%$ & $2.8 \%^{\wedge}$ & $1.7 \%^{\wedge}$ & $1.2 \%$ & $0.9 \% *$ & $0.3 \%$ \\
\hline Podkarpackie [n = 44I] & $51.9 \% \wedge$ & $46.3 \% *$ & $1.8 \% \wedge$ & $0^{\wedge}$ & $0 *$ & 0 & 0 \\
\hline Podlaskie [n = 382] & $19.1 \%^{\wedge}$ & $80.9 \%^{\wedge}$ & $0^{\wedge}$ & $0^{\wedge}$ & $0 *$ & 0 & 0 \\
\hline Świętokrzyskie [n = I23] & $15.1 \%$ *** & $14.4 \% \wedge$ & $23.8 \% \wedge$ & $30.2 \%^{\wedge}$ & $9.0 \% \wedge$ & $5.7 \% \wedge$ & $0.8 \%$ \\
\hline \multicolumn{8}{|l|}{ North-western Region } \\
\hline Wielkopolskie [n = 20I4] & $30.1 \%$ & $53.9 \%$ & $10.0 \%^{\wedge}$ & $3.4 \%$ & $1.3 \%$ & $0.2 \%$ & $0.1 \%$ \\
\hline Zachodniopomorskie [n = 480] & $32.2 \%$ & $57.5 \%$ & $7.9 \%$ & $3.2 \%$ & $0.2 \% *$ & 0 & 0 \\
\hline \multicolumn{8}{|l|}{ South-western Region } \\
\hline Dolnośląskie [n = 828] & $20.5 \%^{\wedge}$ & $65.8 \% * *$ & $6.1 \%$ & $6.0 \% * *$ & $1.0 \%$ & $0.6 \%$ & 0 \\
\hline Opolskie [n = 463] & $35.3 \%$ & $64.4 \%$ & $0.3 \%^{\wedge}$ & $0^{\wedge}$ & 0* & 0 & 0 \\
\hline \multicolumn{8}{|l|}{ Northern Region } \\
\hline Kujawsko-Pomorskie [n = 734] & $39.2 \% * *$ & $54.1 \%$ & $1.8 \%^{\wedge}$ & $2.0 \%$ *** & $1.9 \%$ & $0.7 \%$ & $0.3 \%$ \\
\hline Pomorskie $[\mathrm{n}=778]$ & $41.1 \%^{\wedge}$ & $31.6 \%^{\wedge}$ & $16.3 \%^{\wedge}$ & $8.4 \%^{\wedge}$ & $2.6 \% * *$ & 0 & 0 \\
\hline Warmińsko-Mazurskie $[n=160]$ & $6.6 \% \wedge$ & $92.7 \% \wedge$ & $0.7 \% * *$ & $0 *$ & 0 & 0 & 0 \\
\hline
\end{tabular}

Statistical significance in relation to "Poland" $\chi^{2}-{ }^{*} \mathrm{p}<0.05$; ** $<0.01$; $\wedge \mathrm{p}<0.00$ I

gnosed in Poland more and more often. In view of the ongoing changes, the percentage of patients with venous insufficiency decreases. This percentage decreased from $10 \%$ at the turn of the century [4] to $6 \%$, as this research shows. Currently, ChVD is diagnosed in every third patient (31.9\%) merely on the basis of ailments with no telangiectasias, venulectasias, varices and skin lesions (stage $C_{0}$ ). This percentage is higher than the one indicated by Beebe-Dimmer and colleagues (23.6\% - after recounting for ChVD patients) [I]. Patients in stage $C_{1}-56.1 \%$ constituted the biggest group of patients. However,(active or healed) venous ulcers occurred among $0.6 \%$ of subjects not taking phlebotropic drugs on a regular basis, over two times less than in the research carried out by Jawien and colleagues (1.5\%) [4]. The prevalence of the ChVD stages essentially deviated from the one indicated by Beebe-Dimmer and colleagues [ 1$]$ : stage $C_{1}-26.0 \%$, $\mathrm{C}_{2}-17.9 \%, \mathrm{C}_{3}-\mathrm{C}_{6}-29.1 \%$ (values recounted for the ChVD patients).

The patients with stages $\mathrm{C}_{2}-\mathrm{C}_{6}(\mathrm{I} \%$ ) were considerably less involved in the presented research. The main reason for this were most probably the inclusion criteria for the participation in this study - exclusion of patients taking phlebotropic drugs on a regular basis.

The prevalence of the ChVD stages differed essentially in respective voivodeships. Significant diversity, even within the regions, points rather to essential variations of applied diagnostic criteria as a consequence of an insufficient awareness of the international CEAP classification. This is caused by the marginalization of ChVD in the training programmes of family doctors and internists in the past and a relatively weak dissemination of scale among doctors who are not engaged in treating vascular diseases.

The most frequently reported symptoms and ailments of ChVD are: heaviness of legs (72.9\%), ankle swelling during the evening hours $(68.4 \%)$ and nighttime leg cramps (58.6\%).

Symptoms which occurred less frequently in the study group of patients were leg swelling during evening hours $-39.8 \%$, paraesthesias - $30.4 \%$, restless legs syndrome - $18.6 \%$. It should be emphasized that the prevalence of the symptoms showed significant territorial diversity which resulted neither from the differences 


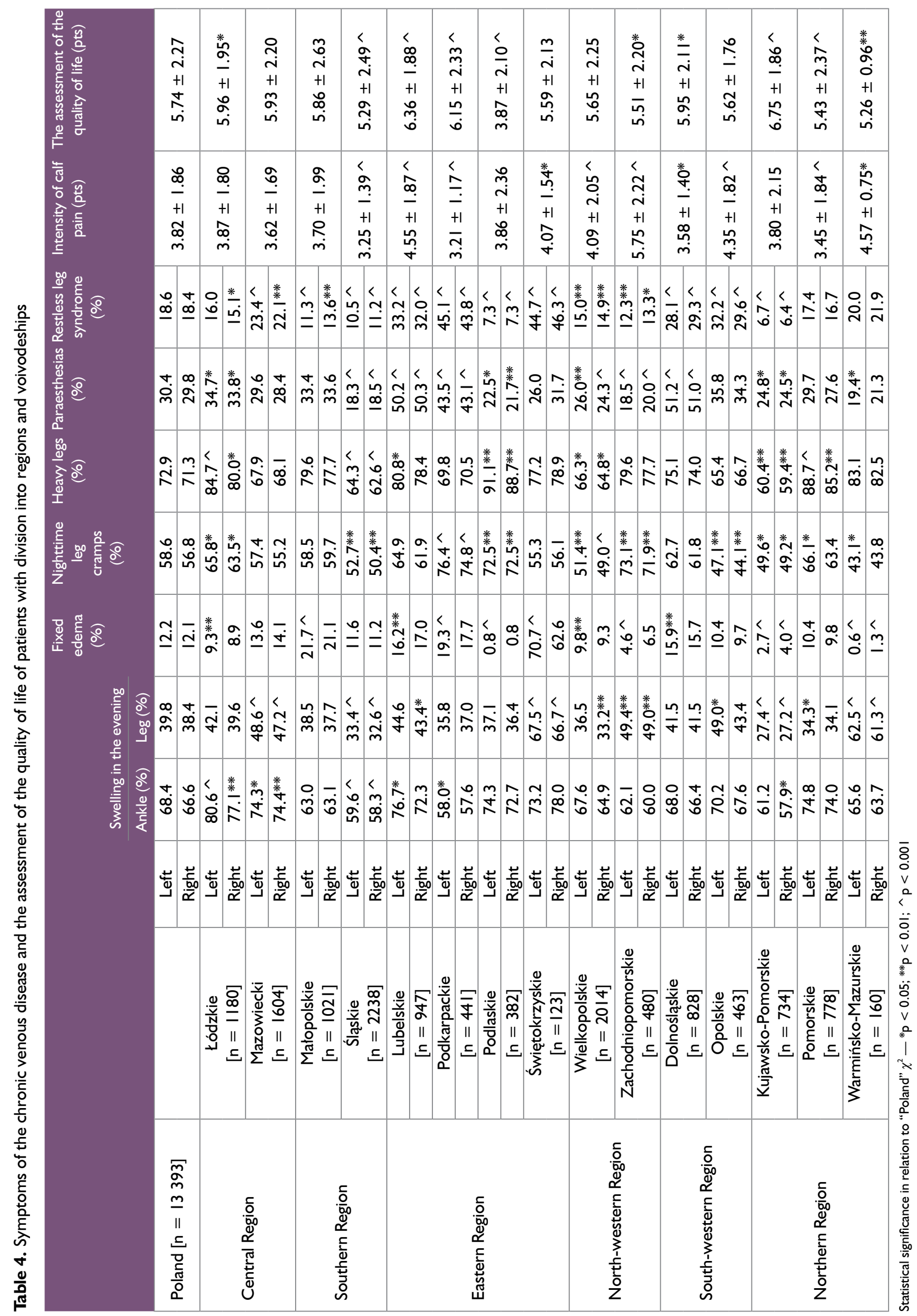


Table 5. Frequency of applying compression therapy and phebotropic drugs by patients suffering from chronic venous disease with division into regions and voivodeships

\begin{tabular}{|c|c|c|c|c|c|}
\hline & \multicolumn{4}{|c|}{ Compression therapy (\%) } & \multirow{2}{*}{$\begin{array}{l}\text { Phlebotropic drugs } \\
\text { in the past (\%) }\end{array}$} \\
\hline & In total & Stockings/tights & Knee socks & Bandages & \\
\hline Poland [n = 13 393] & 12.5 & 5.2 & 5.4 & 2.1 & 24.7 \\
\hline \multicolumn{6}{|l|}{ Central Region } \\
\hline Łódzkie [n = 1180$]$ & $10.2^{*}$ & $3.8^{*}$ & 4.2 & 2.2 & $28.6 *$ \\
\hline Mazowieckie [n = 1604] & $16.5^{\wedge}$ & $6.5^{*}$ & $8.2^{\wedge}$ & 1.8 & $31.7^{\wedge}$ \\
\hline \multicolumn{6}{|l|}{ Southern Region } \\
\hline Małopolskie [n = 102I] & $20.0^{\wedge}$ & $7.9^{\wedge}$ & $10.0^{\wedge}$ & 2.1 & $35.1^{\wedge}$ \\
\hline Śląskie [n = 2238] & $9.4^{\wedge}$ & 4.0* & $3.8 * *$ & 1.6 & $19.6^{\wedge}$ \\
\hline \multicolumn{6}{|l|}{ Eastern Region } \\
\hline Lubelskie [n = 947] & $20.3^{\wedge}$ & $9.9^{\wedge}$ & $7.7 * *$ & 2.7 & $36.6^{\wedge}$ \\
\hline Podkarpackie $[\mathrm{n}=44 \mathrm{I}]$ & $20.2^{\wedge}$ & $12.9^{\wedge}$ & 5.4 & 1.9 & 29.5 \\
\hline Podlaskie [n = 382] & $3.4^{\wedge}$ & $0^{\wedge}$ & 3.4 & $0 * *$ & $14.4^{\wedge}$ \\
\hline Świętokrzyskie [n = 123] & $4.1^{\wedge}$ & 1.7 & $0.8^{*}$ & 1.6 & $56.1^{\wedge}$ \\
\hline \multicolumn{6}{|l|}{ North-western Region } \\
\hline Wielkopolskie [n = 2014] & $9.0^{\wedge}$ & $4.0 *$ & $3.1^{\wedge}$ & 1.9 & $19.4^{\wedge}$ \\
\hline Zachodniopomorskie $[\mathrm{n}=480]$ & $28.8^{\wedge}$ & $11.0^{\wedge}$ & $11.9^{\wedge}$ & $5.9^{\wedge}$ & $11.2^{\wedge}$ \\
\hline \multicolumn{6}{|l|}{ South-western Region } \\
\hline Dolnośląskie [n = 828] & $9.3 *$ & 3.7 & $2.5^{\wedge}$ & 3.1 & 23.7 \\
\hline Opolskie [n = 463] & 14.3 & 6.1 & 6.5 & 1.7 & 23.1 \\
\hline \multicolumn{6}{|l|}{ Northern Region } \\
\hline Kujawsko-Pomorskie [n = 734] & $8.0 * *$ & 4.8 & $2.2^{\wedge}$ & $1.0 *$ & $20.0 *$ \\
\hline Pomorskie $[\mathrm{n}=778]$ & $8.0^{\wedge}$ & $0.9^{\wedge}$ & 4.8 & 2.3 & $12.6^{\wedge}$ \\
\hline Warmińsko-Mazurskie [n = 160] & 8.8 & $1.3 *$ & 5.0 & 2.5 & 21.9 \\
\hline
\end{tabular}

Statistical significance in relation to „Poland” $\chi^{2}-{ }^{*} \mathrm{p}<0.05 ;{ }^{* *} \mathrm{p}<0.01 ; \wedge \mathrm{p}<0.001$

in the ChVD intensity, nor the age of the patients. Also in this case, a considerable diversity of the frequency of symptoms between voivodeships belonging to the regions implies rather variations in collecting detailed survey data by respective doctors, resulting from professional experience. Such an interpretation is also backed up by a significant percentage of patients (12\%) with symptoms of lower limb atherosclerosis, despite the fact that they have been placed in the exclusion criteria of the ankle-brachial index $(A B I<0.85)$.

In the study group every fourth patient took phlebotropic drugs in the past and $12.5 \%$ of patients applied compression therapy. These values cannot be applied to the frequency of applying treatment methods among patients with the diagnosed ChVD, because in some patients this disease entity was not diagnosed earlier. Attention should be drawn to the structure of the used compression products. Knee socks and stockings/tights were used with the same prevalence $(5.4 \%$ and $5.2 \%$ respectively). Using stockings/tights is more efficient in most cases, yet due to the discomfort of putting them on, the use of knee socks is "the lesser evil" than not applying compression therapy at all.

It is difficult to explain the considerable diversity in the frequency of using phlebotropic drugs among patients in different voivodeships (from I I.2 to $56.1 \%$ ).

The presented differences cannot be explained by the variability of ChVD progression, at least the one reported here. It is perhaps a consequence of a different training system of family doctors in the field of ChVD treatment in respective voivodeships.

The limitations of the conducted analysis result from the research methodology - recruiting patients who did not use phlebotropic drugs in the past or who discontinued this therapy. Hence, the study did not cover patients taking phlebotropic drugs on a regular basis. On the other hand, this study allows to assess the frequency of ChVD symptoms in a more reliable way, as they are not disturbed by the intake of these drugs. 


\section{Conclusions}

There is a significant territorial diversity in Poland in the frequency of the reported symptoms and of the conservative therapy of the chronic venous disease. The differences in the frequency of diagnosing the respective stages of the chronic venous disease are most probably caused by the insufficient awareness of the diagnostic criteria of the international CEAP scale by a substantial number of PHC doctors.

\section{References}

I. Beebe-Dimmer JL, Pfeifer JR, Engle JS, Schottenfeld D (2005) The epidemiology of chronic venous insufficiency and varicose veins. Ann Epidemiol; 15: 175-184.

2. Rabe E, Guex JJ, Puskas A, Scuderi A, Fernandez Quesada F (2012) Epidemiology of chronic venous disorders in geograph- ically diverse populations: results from the Vein Consult Program. Int Angiol; 31: 105-II5.

3. Eklöf B, Rutherford RB, Bergan JJ et al (2004) Revision of the CEAP classification for chronic venous disorders: consensus statement. J Vasc Surg; 40: 1248-1252.

4. Jawien A, Grzela T, Ochwat A (2003) Prevalence of chronic venous insufficiency in men and women in Poland: multicentre cross-sectional study in 40,095 patients. Phlebology; 18: I10-122.

5. Ziaja D, Kocełak P, Chudek J, Ziaja K (20II) Compliance with compression stockings in patients with chronic venous disorders. Phlebology; 26: 353-360.

6. Chudek J (2008) Skuteczność i tolerancja diosminy w leczeniu chorych z przewlekłą niewydolnością żylną w codziennej praktyce klinicznej. Probl Med Rodz; 10: 45-5।.

7. Chudek J, Kocełak P, Ziaja D, Owczarek A, Ziaja K (2012) Compliance in pharmacotherapy in patients with chronic venous disorders. Int Angiol; 31: 393-40I. 